\title{
Carbon C11 Temozolomide
}

National Cancer Institute

\section{Source}

National Cancer Institute. Carbon C11 Temozolomide. NCI Thesaurus. Code C113806.

A radioconjug ate composed of temozolomide, a imidazotetrazine analog of dacarbazine, labeled with the radioisotope carbon C11, with potential positron emission tomography (PET) imaging activity. As a cytotoxic alkylating agent, temozolomide is hydrolyzed at physiologic $\mathrm{pH}$ to the pharmacologically active compound, 5-(3-methyl-(triazen-1-yl)imidazole)-4-carboxamide (MTIC). MTIC is further hydrolyzed to 5-aminoimidazole-4carboxamide (AIC) and a methyldiazonium cation. The cation is able to methylate DNA, particularly at the $\mathrm{O} 6$ and N7 positions of guanine residues, resulting in cell cycle arrest, inhibition of DNA replication and the induction of apoptosis. Temozolomide is metabolized to MITC at all sites, crosses the blood-brain-barrier and penetrates well into the central nervous system. Upon PET, the biodistribution, uptake in cancer cells and the efficacy of temozolomide can be assessed. 